Angela D. Bardick and Kerry B. Bernes are with the University of Lethbridge, Alberta, Canada. E-mail: abardick@shaw.ca

\title{
A Closer Examination of Bipolar Disorder in School-Age Children
}

Children who present with severe behavioral concerns may be diagnosed as having other commonly diagnosed childhood disorders, such as attention deficit byperactivity disorder, oppositional defiant disorder, and/or conduct disorder, among others, when they may be suffering from early-onset bipolar disorder. Awareness of the symptoms of early-onset bipolar disorder may lead to appropriate referrals for assessment and treatment, as well as collaborative program planning for children with bipolar disorder. Implications and recommendations for school counselors are discussed.

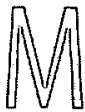
any teachers and parents are not sure where to turn when a child presents with severe behavioral concerns. Early-onset bipolar disorder is often difficult to recognize and diagnose because distinguishing between normal behaviors and pathological behaviors in children can be challenging, and because symptoms of bipolar disorder may resemble those of, and/or co-occur with, other common childhood-onset mental disorders (Bowring \& Kovacs, 1992; National Institute of Mental Health [NIMH], 2000; Papolos \& Papolos, 1999). NIMH (2000) emphasizes the importance of increased understanding and knowledge of the diagnosis and treatment of bipolar disorder in youth.

The American School Counselor Association (ASCA) recognizes that students diagnosed with psychological or behavioral problems will likely experience difficulties with performance at school, at home, and in the community. This article addresses difficulties with the diagnosis of bipolar disorder in children; provides a description of bipolar disorder in adults and children; presents a case study; discusses appropriate assessment, treatment, and program planning for children; and discusses implications and recommendations for school counselors according to the ASCA National Standards for School Counseling Programs.

Bipolar disorder in children often is misdiagnosed and misunderstood. The established criteria for bipolar disorder are based on adult symptoms, which vary greatly from children's symptoms
(NIMH, 2000; Papolos \& Papolos, 1999). Bipolar disorder often is overlooked because a majority of children with symptoms of bipolar disorder also may meet the criteria for more commonly known childhood disorders such as attention deficit hyperactivity disorder (ADHD) (NIMH; Popper, 1996), oppositional defiant disorder (ODD), and conduct disorder (CD) (Kovacs \& Pollock, 1995; NIMH), as well as anxiety disorders (Bashir, Russell, \& Johnson, 1987; Wozniak et al., 1995) and schizophrenia (Carlson, Fennig, \& Bromer, 1994). Symptom overlap, especially with ADHD (Wozniak et al.), makes it difficult to obtain an accurate diagnosis and may result in treatment that worsens, rather than stabilizes, the disorder.

In order to understand how bipolar disorder may be more accurately assessed and diagnosed in children, we first must understand the symptoms of the disorder in adults, and then review how the presentation of the disorder differs in school-age children.

\section{BIPOLAR DISORDER IN ADULTS}

According to the Diagnostic and Statistic Manual of Mental Disorders, Fourth Edition, Text Revision (DSM-IV-TR), adults with bipolar disorder typically experience a pattern of mood swings ranging from hypomania or mania (which includes increased rates of thinking and activity, energy surges, heightened creativity and sexuality, and less need for sleep) to depression (which includes difficulty making decisions, sleep disturbances, low energy levels, lack of interest in sex, appetite disturbances, and difficulties with concentration and attention), with potential intervals of wellness between manic and depressive episodes (American Psychiatric Association, 2000). An adult experiencing a manic "high" may spend money impulsively, make reckless decisions, commit sexual indiscretions, and/or experience rapid mood swings. Bipolar I refers to individuals who experience depression alternating with out-of-control or psychotic mania, and Bipolar II refers to those who suffer depression and experience hypomanic 
episodes without loss of control or psychosis. According to the DSM-IV-TR, rapid cycling occurs if an individual experiences four or more episodes per year (American Psychiatric Association). Earlyonset bipolar disorder frequently presents very differently in children than bipolar disorder in adults.

\section{BIPOLAR DISORDER IN CHILDREN}

Children with early-onset bipolar disorder rarely fit the classical pattern of bipolar disorder in adults, so using adult criteria to diagnose children may result in a misdiagnosis. Children with early-onset bipolar disorder may present with a wide variety of symptoms that range from mild to extreme and that may begin as early as infancy (Papolos \& Papolos, 1999). These may include irritability, unpredictability, hyperactivity and attention problems, conduct problems, social problems, childhood depression, eating disorders, self-mutilation, and suicidal ideation (NIMH, 2000; Papolos \& Papolos).

Major depression may be one of the first manifestations of early-onset bipolar disorder. Studies have shown that approximately one third of children who first appear to be suffering from depression may later manifest symptoms of bipolar disorder (Geller, Fox, \& Clark, 1994; Lewinsohn, Klein, \& Seely, 1995; State, Altshuler, \& Frye, 2002). Depression in children may appear as frequent crying, loss of interest in enjoyable activities, changes in appearance (e.g., lack of self-care), increased irritability, changes in sleeping patterns (e.g., too much or too little sleep), and increased social withdrawal (Papolos \& Papolos, 1999).

Wozniak et al. (1995) states that severe irritability is often a predominant mood in children meeting the criteria for mania. Impending mania also may appear as an increase in behaviors such as being silly, giddy, goofy, or mouthy, having grandiose ideas (e.g., that they can teach better than the teacher), speaking rapidly, having racing thoughts, having bizarre hallucinations, making outrageous comments, and exhibiting hypersexuality (e.g., making sexualized comments) (Papolos \& Papolos, 1999). Behavior may become very goal-directed (e.g., taking out materials to begin working on a project that must be completed immediately).

Mixed states and rapid cycling have been reported in over 70 percent of children diagnosed with earlyonset bipolar disorder (State et al., 2002). A mixed state is marked by agitation, high energy, and constant restlessness coupled with feelings of worthlessness and self-destruction (Papolos \& Papolos, 1999). Rapid cycling is defined as rapid transitions between depressive and manic symptoms (American Psychiatric Association, 2000). Ultra-rapid cycling may last a few days to a few weeks, and ultradian (ultra-ultra-rapid) cycling may occur within a 24 hour period (Geller et al., 1998).

Many children with bipolar disorder exhibit symptoms associated with $\mathrm{ADHD}$, such as distractibility, motor hyperactivity, and overtalkativeness (Hazell, Carr, Lewin, \& Sly, 2003). It is not known whether these disorders may coexist, if hyperactivity precludes mania, or if there is symptom overlap (State et al., 2002). Faraone et al. (1997) suggested that, in some cases, $\mathrm{ADHD}$ may be an early marker of early-onset bipolar disorder. Geller and Luby (1997) reported that 90 percent of children and 30 percent of adolescents with bipolar disorder also may have ADHD. Biederman et al. (1996) found that the lifetime prevalence of bipolar disorder in a sample of children and adolescents with ADHD doubled over a 4-year period, increasing from 11 percent to 23 percent. Thus, it is important to note that although symptoms or a diagnosis of $\mathrm{ADHD}$ are present, something more than ADHD may be going on.

Children with early-onset bipolar disorder may exhibit symptoms associated with ODD or CD, such as defiance, refusal to comply with adults' requests, and deliberately annoying people (Kovacs \& Pollock, 1995). Frequent lying and manipulation of others may be another comorbid symptom of bipolar disorder and ODD/CD (Papolos \& Papolos, 1999). Geller and Luby (1997) found that approximately 22 percent of children and 18 percent of adolescents with bipolar disorder demonstrated features of $\mathrm{CD}$, such as poor judgment and grandiose behaviors, as initial manifestations of early-onset bipolar disorder.

Substance abuse also may become a comorbid condition during the teenage years (Geller \& Luby, 1997). Children with bipolar disorder also may experience intense cravings for carbohydrates and sweets. Many females suffering from bipolar disorder also suffer from coexisting eating disorders such as anorexia (self-induced starvation) or bulimia (bingeing and purging) (Bock, 1999).

Some children with bipolar disorder may have difficulty with peers because they are unable to respond appropriately to social clues or boundaries. Parents may describe their bipolar children as "bossy," "intrusive," "has to have his or her own way or the game is over," or "too overwhelming and aggressive" (Papolos \& Papoplos, 1999, p. 18). So m e children with bipolar disorder may rake their arms with razors, pins, or other sharp objects, hit themselves, or bang their heads against a wall in an attempt to self-mutilate (Papolos \& Papolos). Probably the most dangerous symptom of bipolar disorder is suicidal ideation, even in children as young as 4 years of age (Papolos \& Papolos). There is a higher risk of suicidality among bipolar adolescents compared to adolescents with other diagnoses

\section{Early-onset bipolar \\ disorder is often \\ difficult to \\ recognize and \\ diagnose because \\ distinguishing \\ between normal \\ behaviors and \\ pathological \\ behaviors in \\ children can be \\ challenging.}


(Brent et al., 1993). Hospitalization may need to be considered if a child is so out of control that he or she is unable to stop raging, experiencing delusions or hallucinations, threatening to harm others, harming himself or herself, or threatening suicide. The high prevalence of suicidality combined with the rapidity of cycling means that serious suicidal risk may appear without warning (Geller et al., 1998).

The above-noted behaviors may be setting-specific. A child may act one way at home and another way at school, causing confusion for parents and teachers. The wide range of behavioral and mood-related symptoms associated with early-onset bipolar disorder, as discussed above, serves to complicate making an accurate diagnosis.

\section{Children with early-}

onset bipolar

disorder rarely fit

the classical

pattern of bipolar

disorder in adults,

so using adult

criteria to diagnose

children may result

in a misdiagnosis. differences. Normal developmental symptoms and

\section{DIAGNOSIS}

Children with bipolar disorder may be "among the most challenging children to diagnose" (State et al., 2002). There are no scales to rely on, no specific lab tests, a variety of overlapping symptoms with other psychiatric disorders, and a wide range of individual stages further affect problems with diagnosis (Papolos \& Papolos, 1999). Medical conditionssuch as diabetes, thyroid problems, iron-deficiency anemia, cancer, and chronic fatigue syndrome, among many others-may include symptoms that mimic depression or mania (Papolos \& Papolos). Medical conditions such as these must be ruled out by a complete physical examination with laboratory tests. A complete medical exam, assessment by a child psychiatrist, family history, social history, selfreports, and observations of behavior are necessary to arrive at a diagnosis, and even then there may be a significant amount of ambiguity. Once a diagnosis has been made by an appropriate professional, early intervention is imperative.

\section{EARLY INTERVENTION}

Early intervention can help to stabilize children who experience overwhelming mood changes and rages as well as to provide hope for their future. As well, it is important to prevent other difficulties associated with adolescent bipolar disorder, such as engaging in risky behaviors, hypersexual behavior leading to unwanted pregnancy and/or sexually transmitted diseases, reckless driving, and the possibility of substance abuse (Papolos \& Papolos, 1999). Early intervention helps families to obtain appropriate services and supports and to make plans for the future. Early intervention may lead to a diagnosis that explains much of the behavioral and emotional experiences of the child as well as guides treatment. As an example of the importance of early inter- vention, a case study of a child recently diagnosed with early-onset bipolar disorder is examined.

\section{CASE STUDY OF A 9-YEAR-OLD MALE}

This male child was born after a full-term pregnancy and delivery by vacuum extraction. He was always at the 50th percentile for height and weight and met all developmental milestones within normal time limits. Behavior difficulties were first noted between the ages of 2 and 3 , when he would yell and bang his head at day care, aggressively hit, kick, and bite others, and thrash around in a tantrum over something simple. Most of the time, he was enthusiastic, helpful, and constantly on the move, but he would fly into a rage over nothing within minutes.

This child continuously complained of headaches, stomach problems, and difficulty swallowing, and he had frequent diarrhea. At age 5 , his family doctor referred him to a psychiatrist because of his behavior, who found that he met the criteria for ADHD and ODD. His school referred him for psychological testing, where it was found he was of average intelligence, with a giftedness in math. The psychologist also found that he had many symptoms associated with ADHD, impulsivity disorder, and severe ODD. His mother chose not to start him on Ritalin because of the risk of side effects.

His Individual Program Plans (individualized educational programs designed for students identified with cognitive or behavioral difficulties in Canadian schools) from kindergarten to Grade 3 consisted of strategies to work on anger management, cooperation, behavior, and reading, as well as enrichment activities for math. His teachers reported that his behavior gradually improved, but that he would become very anxious when completing timed math facts. At one time before completing timed math facts, he became so anxious that he began screaming and banging his head against the wall. He continuously worried about getting good grades, was often bossy on the playground, did not have many friends, and would become explosive in group activities. His stories were creative and consisted of dragons, blowing up the world, sea monsters, and constant conflict. He talked incessantly and with great detail.

He reported to the school counselor, and later to a social worker, that he had been spanked, threatened, yelled at, sworn at, and made to stay up all night doing hours of homework. In referring to living at home, he said that sometimes it was as bad as "Frankenstein having his head cut off and sewn back on and being brought back to life. Do that 100 times and that's how bad it is." As a result, he was taken into custody by a child protection worker because of concerns about physical and emotional abuse. 
While in custody, he repeatedly ran away and exhibited more extreme behaviors. He threatened to kill the foster family's dog and to throw himself in front of a van, and he stated that if he had a knife or a gun he would "kill everyone then kill himself." His behavior became so extreme that he was hospitalized. After being released, he continued making threats to harm himself and others, banging his head against the wall, and needed to be restrained. $\mathrm{He}$ again was taken to the hospital but was refused admission because they would not deal with a child with behavioral problems, stating that he "needed some discipline," and that one could not take threats of suicide seriously from a 9-year-old child.

The mother voluntarily underwent a full parenting assessment, and none of the physical or emotional abuse concerns were substantiated. In response to her child's reports of physical abuse, she reported that he would punch and kick her, and she would restrain him and send him to his room. In response to his reports of being made to "stay up all night to do homework," she reported that she knew he was gifted in math, so she saw no reason for him to have difficulty with timed math facts and had him practice for a half hour each night.

It is understandable that this child's behaviors initially were attributed to ADHD and ODD; however, several clues were missed during the assessment and observation of this child. Despite his hyperactivity, he was able to focus on a project for 1 to 2 hours at a time. As well, he demonstrated extreme variety and vacillation of moods, or rapid cycling. His father was reported to have been diagnosed with bipolar disorder, and his mother had been diagnosed with major depression, which points to a bilateral transmission of the disorder. His ability to focus, rapid mood changes, and family history combined with years of behavior problems narrowed the diagnosis down to early-onset bipolar disorder. Fortunately for this child, appropriate pharmacological and psychotherapeutic treatment stabilized his moods and behaviors, allowing him to do well at school and at home.

\section{IMPLICATIONS FOR SCHOOL COUNSELORS}

When faced with a child who presents with severe behavioral problems, school counselors' primary roles center around the ASCA's National Standards in academic development and personal/social development. The following recommendations are based on the ASCA position on ADHD (ASCA, 2000) and recommended interventions for children with behavioral disorders. The school counselor may participate in the implementation of the following: (a) making referrals for appropriate assessment and treatment; (b) developing a collaborative relationship with parents and teachers so as to facilitate a multimodal delivery of services to children with bipolar disorder; (c) helping teachers design appropriate programs for students that include opportunities to learn appropriate social skills and self-management skills; (d) providing students with activities to improve their self-esteem and self-concept and to promote the safety of self and others; (e) and serving as a consultant and resource to parents, teachers, and other school personnel on the characteristics and problems of students with bipolar disorder.

School counselors need to be aware that children who present with severe behavioral concerns need to be thoroughly assessed and treated by a child psychiatrist and/or child psychologist. In these situations, the role of the school counselor is to encourage parents to have the child assessed so that apprepriate provisions may be made at the school level to accommodate the child's needs. It is recommended that school counselors and teachers document dates and severity of behaviors that are a cause for concern in order to help appropriate health-care providers arrive at an accurate diagnosis. Continued documentation of behaviors after diagnosis and during treatment is important to monitor progress and to help fine-tune treatment requirements.

The development of a collaborative relationship among the school counselor, parents, and teachers is important for a plan for working with the bipolar child. Counselors may play a role in helping teachers give the child a sense of consistency throughout his or her day by maintaining open communication with parents to identify effective strategies to be used at both home and school. Working with parents and teachers to identify inciting events that may set off a child's negative behavior may be helpful in both the home and school setting. For example, the child in the case example became easily frustrated when doing timed math facts at both home and school. When given the opportunity to complete math facts without the pressure of being timed, his frustration level dropped and he experienced success. A daily home-school communication log may become an important tool to ensure that everyone receives the same information and adjusts the child's schedule or work expectations accordingly. For example, if a child had a difficult time sleeping the previous night, it may be expected that he or she may not be functioning at an optimal level at school the next day. Therefore, providing the child with a quiet space to work, opportunities to take more breaks, or a reduced workload may be appropriate.

Children with bipolar disorder may be defiant and resistant to suggestions from adults, resulting in conflict. Greene (1996) has recommended that parents and teachers prioritize items into three "bas-

\section{Mixed states and \\ rapid cycling have \\ been reported in \\ over 70 percent of \\ children diagnosed \\ with early-onset \\ bipolar disorder.}




\section{Early intervention}

can help to stabilize

children who

experience

overwhelming

mood changes and

rages as well as to

provide hope for

their future. kets" in order to reduce behavioral difficulties. The purpose of the baskets is to identify behaviors that are non-negotiable, negotiable, and not worth addressing. "Basket $A$ " consists of non-negotiable items that parents and teachers should insist upon, such as unsafe behaviors that could be harmful to the child, other people, animals, or property (e.g., anything that requires a firm "No"). "Basket B" consists of items that are negotiable, that are important to teach the child how to stay calm in the midst of frustration, and that require the adult to work with the child to arrive at a mutually satisfactory resolution. Greene suggests using the question "Can you think of a way to work that out?" to encourage children to think about possible solutions, rather than overreacting to the problem. For example, completing timed math facts is not a safety issue (Basket A), therefore, it is negotiable (Basket B). The adult would calmly and rationally identify the reason for not wanting to complete timed math facts and negotiate with the child an appropriate manner in which to complete the math facts. "Basket C" consists of items that are not worth fighting about (e.g., no-win situations). For example, for some children in certain mood states, completing math facts may be a no-win situation, and therefore, the adult would not even address the situation until a later time.

Counselors need to recognize that the bipolar child's behaviors are stimulated by internal rather than external factors but may be easily set off by external cues (Papolos \& Papolos, 1999). Therefore, children with bipolar disorder require special accommodations at school, specifically in regard to overstimulation, transitions, and social interactions (Papolos \& Papolos). By developing a collaborative working relationship with parents and teachers, school counselors may be able to work with the classroom teacher to make accommodations for the child with bipolar disorder. School counselors may need to provide rationales for teachers for them to make necessary accommodations in their classrooms (explaining about internal and external factors that influence the student's behavior). For example, children who become overstimulated may require a place to calm down when their moods are variable. It is recommended that the child be given the opportunity to choose the times when he or she would prefer to work alone, or the child and teacher may develop a signal for use when either of them recognizes that difficulties may occur. Children who have difficulty making transitions may benefit from the use of a written plan for the day so they are aware of the transitions in advance. Children who have difficulty with social interactions may benefit from practicing skills such as staying calm in the midst of frustration, collaborative problem solving, and seeing situations from alternative viewpoints (Greene, 1996).

Personal safety and the safety of others is always an issue. Collaboration with administration, teachers, and parents is necessary to determine where a child will be taken if he or she is in a rage. Removing the child from the classroom or playground and into a space that is safe may be necessary. Some children respond well to being physically restrained by an individual trained in child restraints, whereas other children become more panicky. A child who is raging likely will not respond to verbal intervention by adults, and that child requires space and time to regain control and calm down (Papolos \& Papolos, 1999). It is highly recommended to have a space reserved for children who may experience rages at school, such as a room with no stimulation and no access to materials that may become weapons (Greene, 1996; Papolos \& Papolos).

It is difficult to know how seriously to take a child's threat of suicide (Papolos \& Papolos, 1999). It is a myth that individuals who threaten suicide never actually go through with it, so any threat of suicide from a child of any age needs to be taken seriously. Suicide is often an impulsive act and may be triggered by a variety of events (e.g., relationship problems, difficulty with schoolwork, hurt feelings), so children who threaten suicide need to be closely monitored.

By developing a broad base of knowledge of bipolar disorder in children, the school counselor may act as a consultant or resource person for parents, teachers, and school personnel. Knowing the signs and symptoms associated with early-onset bipolar disorder would lead to appropriate referrals, assessment, and treatment. As a result, collaborative programming may ensue for children with academic, behavioral, and/or social problems associated with early-onset bipolar disorder.

\section{CONCLUSION}

Many children present with behavioral difficulties that may be misdiagnosed and misunderstood. Early-onset bipolar disorder is difficult to diagnose because symptoms overlap with other disorders as well as with normal childhood development. Increased awareness of the symptoms of a potential mood disorder in children may help school counselors refer children for appropriate assessment and treatment. School counselors need to be aware of the symptoms and implications of mood disorders in children, and to collaborate with parents and teachers to make accommodations at school to promote the safety, well-being, and success of the child with bipolar disorder. 


\section{References}

American Psychiatric Association. (2000). Diagnostic and statistical manual of mental disorders (4th ed., text rev.). Washington, DC: Author.

American School Counselor Association. (2000). The professional school counselor and attention deficit/hyperactivity disorder: American School Counselor Association (ASCA) position. Retrieved July 27, 2004, from http://www. schoolcounselor.org/content. $\mathrm{fm}$ ? $\mathrm{L} 1=1000 \& \mathrm{~L} 2=4$

Bashir, M., Russell, J., \& Johnson, G. (1987). Bipolar affective disorder in adolescence: A 10-year study. Australian and New Zealand Journal of Psychiatry, 21, 36-43.

Biederman, J., Faraone, S., Mick, E., Wozniak, J., Chen, L., Ouellette, C., et al. (1996). Attention-deficit hyperactivity disorder and juvenile mania: An overlooked comorbidity? Journal of the American Academy of Child and Adolescent Psychiatry, 35, 997-1008.

Bock, L. P. (1999). Differential diagnoses, co-morbidities, and complications of eating disorders. In R. Lemberg \& $\mathrm{L}$. Cohn (Eds.), Eating disorders: A reference sourcebook (pp. 41-43). Phoenix, AZ: The Oryx Press.

Bowring, M. A., \& Kovacs, M. (1992). Difficulties in diagnosing manic disorders among children and adolescents. Journal of the American Academy of Child and Adolescent Psychiatry, 31, 611-614.

Brent, D. A., Perper, J. A., Moritz, G., Allman, C., Friend, A., Roth, C., et al. (1993). Psychiatric risk factors for adolescent suicide: A case-control study. Journal of the American Academy of Child and Adolescent Psychiatry, 32, 521-529.

Carlson, G. A., Fennig, S., \& Bromet, E. J. (1994). The confusion between bipolar disorder and schizophrenia in youth: Where does it stand in the 1990s? Journal of the American Academy of Child and Adolescent Psychiatry, 28, 221-228.

Faraone, S. V., Biederman, J., Wozniak, J., Mundy, E., Mennin, D., \& O'Donnell, D. (1997). Is comorbidity with ADHD a marker for juvenile-onset mania? Journal of the American Academy of Child and Adolescent Psychiatry, 36, 1046-1055.

Geller, B., Fox, L., \& Clark, K. (1994). Rate and predictors of prepubertal bipolarity during follow-up of 6- to 12-year-old depressed children. Journal of the American Academy of Child and Adolescent Psychiatry, 33, 461-468.

Geller, B., \& Luby, J. (1997). Child and adolescent bipolar disorder: A review of the past 10 years. Journal of the American Academy of Child and Adolescent Psychiatry, 36, 1168-1176.
Geller, B., Williams, M., Zimmerman, B., Frazier, J., Beringer, L., \& Warner, K. L. (1998). Prepubertal and early adolescent pibolarity differentiate from ADHD by manic symptoms, grandiose delusions, ultra-rapid or ultradian cycling. Journal of Affective Disorders, 51, 81-91.

Greene, R. J. (1996). The explosive child. New York: Harper Collins.

Hazell, P. L., Carr., V., Lewin, T. J., \& Sly, K. (2003). Manic symptoms in young males with $A D H D$ predict functioning but not diagnosis after 6 years. Journal of the American Academy of Child and Adolescent Psychiatry, 42, 552-561.

Kovacs, M., \& Pollock, M. (1995). Bipolar disorder and comorbid conduct disorder in childhood and adolescence. Journal of the American Academy of Child and Adolescence, 34, 715-723.

Lewinsohn, P. M., Klein, D. N., \& Seely, J. R. (1995). Bipolar disorders in a community sample of older adolescents: Prevalence, phenomenology, comorbidity, and course. Journal of the American Academy of Child and Adolescent Psychiatry, 34, 454-463.

National Institute of Mental Health. (2000). Child and adolescent bipolar disorder: An update from the National Institute of Mental Health. Retrieved July 8, 2004, from http://www.nimh.nih.gov/publicat/bipolarupdate.cfm

Papolos, D. F., \& Papolos, J. (1999). The bipolar child:The definitive and reassuring guide to childhood's most misunderstood disorder. New York: Broadway Books.

Popper, C. (1996). Diagnosing bipolar vs. ADHD: A pharmacological point of view. The Link, 13.

State, R. C., Altshuler, L. L., \& Frye, M. A. (2002). Mania and attention deficit hyperactivity disorder in a prepubertal child: Diagnostic and treatment challenges. American Journal of Psychiatry, 159(6), 918-925.

Wozniak, J., Biederman, J., Kiely, K., Ablon, J.S., Faraone, S. V., Mundy, E., et al. (1995). Mania-like symptoms suggestive of childhood-onset bipolar disorder in clinically referred children. Journal of the American Academy of Child and Adolescent Psychiatry, 34, 867-877.

\section{Recommended Resource}

The Bipolar Child: The Definitive and Reassuring Guide to Childhood's Most Misunderstood Disorderhttp://www.bipolarchild.com 


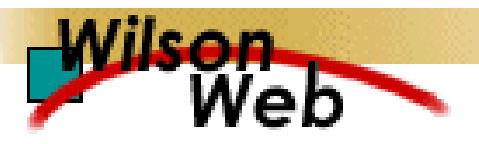

\section{COPYRIGHT INFORMATION}

TITLE: A Closer Examination of Bipolar Disorder in School-Age Children

SOURCE: Prof Sch Couns 9 no1 O 2005

WN: 0527405985013

The magazine publisher is the copyright holder of this article and it is reproduced with permission. Further reproduction of this article in violation of the copyright is prohibited.

Copyright 1982-2005 The H.W. Wilson Company. All rights reserved. 